\title{
Custos da água na produção de cerveja: Uma análise econômica comparativa
}

\author{
Water costs in beer production: A comparative economic analysis \\ Costes del agua en la producción de cerveza: Un análisis económico comparativo
}

Recebido: 08/02/2021 | Revisado: 13/02/2021 | Aceito: 17/02/2021 | Publicado: 22/02/2021

Rafael Felipe Ramos de Rangel Moreira Cavalcanti
ORCID: https://orcid.org/0000-0002-2530-8760
Universidade Federal de Campina Grande, Brasil
E-mail: Rafaelfrrmcavalcanti @ gmail.com
José Erivaldo da Silva
ORCID: https://orcid.org/0000-0001-6682-852X
Universidade Federal de Campina Grande, Brasil
E-mail: jerysilva85@ gmail.com
Isabel Lausanne Fontgalland
ORCID: https://orcid.org/0000-0002-0087-2840
Universidade Federal de Campina Grande, Brasil
E-mail: isabelfontgalland@ gmail.com

\begin{abstract}
Resumo
O Brasil tem crescido bastante no segmento cervejeiro com as grandes fabricantes e com as cervejarias artesanais que surgem constantemente no mercado. Porém, o gasto de água em uma indústria cervejeira pode ser de $4 \mathrm{a} 10$ vezes em relação ao volume de cerveja produzida. Diante da grande quantidade de água necessária na produção de cerveja o trabalho teve como objetivo verificar se o uso da água na produção de cerveja é sustentável, tomando como parâmetro o preço implantado aos utilizadores e os custos pela utilização. Dois métodos de avaliação foram adotados, a construção de uma função de produção e a avaliação da predisposição a pagar pela água na produção.Concluiu-se que ah um investimento em tecnologias pelas principais fábricas de cerveja para preservação dos recursos naturais especialmente a água e que a propensão a pagar pelo recurso é tratada a partir dos discursos dos representantes como já sendo feito a partir dos investimentos em tecnologias para maior impactar no meio ambiente e diminuição das externalidades negativas.
\end{abstract}

Palavras-chave: Sustentabilidade; Recursos hídricos; Economia Ambiental; Cerveja.

\begin{abstract}
Brazil has grown a lot in the beer segment with the big manufacturers and with the craft breweries that appear constantly on the market. However, water use in a brewing industry can be 4 to 10 times greater than the volume of beer produced. In view of the large amount of water needed in beer production, the work aimed to verify whether the use of water in beer production is sustainable, taking as a parameter the price implemented to users and the costs for use. Two assessment methods were adopted, the construction of a production function and the assessment of the willingness to pay for water in production. It was concluded that there is an investment in technologies by the main beer factories for the preservation of natural resources, especially water, and that the propensity to pay for the resource is treated based on the speeches of the representatives as already being done through investments in technologies for greater impact on the environment and reduction of negative externalities.
\end{abstract}

Keywords: Sustainability; Water resources; Environmental Economics; Beer.

\section{Resumen}

Brasil ha crecido mucho en el segmento de la cerveza con los grandes fabricantes y con las tiendas artesanales que aparecen constantemente en el mercado. Sin embargo, el uso de agua en una industria cervecera puede ser de 4 a 10 veces mayor que el volumen de cerveza producida. Dada la gran cantidad de agua necesaria en la producción de cerveza, el trabajo tuvo como objetivo verificar si el uso de agua en la producción de cerveza es sostenible, tomando como parámetro el precio implementado a los usuarios y los costos de uso. Se adoptaron dos métodos de evaluación, la construcción de una función de producción y la evaluación de la disposición a pagar por el agua en la producción. Se concluyó que hubo una inversión en tecnologías por parte de las principales fábricas de cerveza para preservar los recursos naturales, especialmente el agua y que la La propensión a pagar por el recurso se aborda desde los discursos de los representantes como ya se hace desde las inversiones en tecnologías para tener un mayor impacto en el medio ambiente y disminuir las externalidades negativas.

Palabras clave: Sustentabilidad; Recursos hídricos; Economía ambiental; Cerveza. 


\section{Introdução}

A água acompanha historicamente o processo civilizatório da humanidade, ao longo dos tempos tornou-se um bem limitante do processo de desenvolvimento ao qual está inserido o ser humano. Dado o crescimento pela demanda por água registrada mundialmente que desde o final do Século XX vem ocorrendo uma mudança de paradigmas na política de gestão de águas, a remota política de fomento à água começa a ceder lugar então à política do controle, da eficiência e da procura, com crescente introdução de critérios econômico, tais como preços, tarifas e mercados de água (Gleick, 2000).

Nesse sentido, pode se deduzir que a eficiência do uso da água está intimamente ligada a minimização dos desperdícios e da eficiência ótima do recurso, devendo aproximar-se ao máximo a fronteira da eficiência de produção e o valor da produtividade marginal igual aos custos marginais em seus diferentes usos (Fragoso, 2001; Henrique, et al., 2006). Compreendendo que a equidade está ligada ao igual acesso a água e na redistribuição dos rendimentos, os preços da água são parâmetros de aferição da sustentabilidade, quando estes são imputados aos utilizadores, para tanto é importante ressaltar que os custos de exploração e de manutenção e os custos ambientais associados a atividade, promovem de certa forma flexibilidade a implantação dos custos de investimento.

Os resultados eficientes dependem em primeiro lugar de uma política de gestão de águas eficiente, considerando inclusive a recuperação dos custos com a água, porém é freqüente que o equilíbrio orçamentário da oferta seja incompatível com a eficiência e equidade em função dos rendimentos crescentes e a escala do monopólio natural na qual se processa a oferta por água, fator pelo qual pode ser regulada pelas tarifas públicas. (Cordeiro,2003). A política tarifária é um instrumento de regulação econômica da procura por água, que por intermédio das modificações dos preços ou da transferência de rendimentos objetiva influenciar nas decisões dos produtores de cerveja, na tentativa da mudança voluntaria de comportamentos. (Tsur, et al., 2003).

A política tarifaria é fundamentalmente baseada na teoria microeconômica neoclássica, estabelecendo correlação entre oferta e procura o que leva ao entendimento de que pela ótica da procura o ponto ótimo é dado pelo valor da produtividade marginal e pela competição entre os diversos usos do bem nesse caso da água; o uso para a produção de cerveja a procura por água é derivado diretamente dependente dos preços do produto no mercado, da produtividade marginal na função de produção e da competição entre as diversas marcas (Hal, 1992). Do lado da oferta as tarifas têm a pretensão de cobrir os custos com os serviços de abastecimento, os custos de escassez relacionados ao uso do recurso, os custos integrais da oferta e os custos sociais, tais como, os relacionados a poluição, ainda assim, a questão central as tarifas relacionam-se a uma fixação em nível de tarifa que esteja adaptada ao custo marginal ou ao custo médio. (Cordeiro,2003).

A composição dos custos do uso da água na produção de cerveja além dos aspectos acima mencionados, relacionados diretamente aos aspectos econômicos da equação, é necessário considerar o tipo de água a ser utilizada na atividade, a quantidade de água utilizada para a produção de um litro de cerveja, os serviços ambientais que a água deixa de realizar pela decisão de uso na produção de cerveja e, o mais importante os impactos ambientais considerado as externalidades da atividade. A cerveja é uma bebida não destilada, obtida da fermentação alcoólica do mosto de cereal maltado, geralmente malte de cevada. É facultativa a adição de outra matéria-prima amilácea ou lúpulo. Pouco se conhece sobre o surgimento da cerveja no mundo, mas estima-se que a produção da cerveja teve seu início por volta de 8000 a.C. Esta bebida foi desenvolvida paralelamente aos processos de fermentação de cereais. Na Antiguidade, difundiu-se lado a lado com as culturas de milho, centeio e cevado, entre os povos da Suméria, Babilônia e Egito (Mega, et al., 2011).

O Brasil tem crescido bastante no segmento cervejeiro com as grandes fabricantes e com as cervejarias artesanais que surgem constantemente no mercado. Atualmente ocupa a terceira posição no ranking dos maiores produtores com uma média 13 bilhões de litros de cerveja ao ano. Em 2020 o país alcançou a marca de 1.2091 cervejarias registradas em 26 Unidades da 
Federação, onde somente o estado do Acre ainda não possui cervejarias registradas. $\mathrm{O}$ crescimento no número de estabelecimentos se mostra constante nos últimos vinte anos, com uma taxa média de 19,6\% de crescimento por ano. Recentemente esta taxa de crescimento cresceu, sendo de $26,6 \%$ se analisado o período dos últimos 10 anos e $36,4 \%$ no período de 5. Sendo assim foram feitas projeções que se mantida a taxa de 36\% de crescimento até 2025 o país alcançaria a marca de 7.504 cervejarias, o que ultrapassa o número de cervejarias dos EUA no último balanço disponível de 2018 com 7.346 cervejarias. Com uma projeção de crescimento intermediário esse número chegaria perto das 5 mil cervejarias e o mais modesto em 3.5 mil (Anuário da cerveja, 2020).

A água é um dos principais insumos da cerveja sendo então considera para definição dos locais onde as cervejarias serão instaladas. A água utilizada para fabricar cerveja obrigatoriamente tem que ser potável, podendo sofrer correções químicas de acordo com a sua composição (Junior, et al.,2009). Nas cervejarias se tem um consumo específico de água que varia de 4 a 11L por litro de cerveja produzido (Filladeau, et al., 2006; Mathias, et al.,2014).

$\mathrm{Na}$ estação de tratamento de água, há três tipos de água: Água cervejeira (adicionada ao processo), com relação a quantidade de água utilizada nessa etapa não há ainda uma concordância, no entanto calcula-se que no processo de produção de uma cervejaria brasileira, para se produzir 1 litro do produto acabado de cerveja pilsen, utilizam-se em média 8 litros de água. Outro uso é a água industrial (com mais cloro para ser usada na higienização da indústria) e por último a água de utilidades (para caldeira e refrigeração, com baixo teor de cloro e cálcio). Esta água, ao contrário da água cervejeira, deve ter o pH mais alto (Trommer,2011).

Sobre a água cervejeira essa corresponde a 93\% da cerveja, sendo então assim o principal ingrediente. Essa água deve ser inócua, livre de contaminações e dura (com alto teor de cálcio e magnésio) para servir de nutriente para as leveduras fermentativas. O cálcio presente na água também atuará para trazer açúcar para a cerveja. A água também deve ser clorada, sem presença de ferro. $\mathrm{O}$ autor ainda diz que o $\mathrm{pH}$ deve ser ajustado para 5,0. Este ajuste é importante para duas finalidades: Para potencializar o efeito do cloro (que deve estar entre 0,1 a 0,2 ppm de cloro livre, pois acima deste valor há formação de cloranfenicol na cerveja) e pelo efeito da ação enzimática, pois as $\alpha$ e $\beta$ amilases e as proteases presentes nos grãos só atuam em pH baixo (Júnior, et al., 2009). Já em relação ao uso da água no processo de resfriamento o sistema utilizado para o resfriamento é realizado através de trocadores de calor (circuito aberto com a utilização de água no processo), onde a água que se utiliza nesse processo é descartada, a cada processo produtivo, acarretando assim um consumo excessivo de água (Junior \& De Barros,2020).

Portanto, diante das informações apresentadas percebe-se que a indústria cervejeira no Brasil necessita de grande quantidade de água podendo consumir aproximadamente 100 bilhões de litros de água por ano. Sendo assim, o objetivo desse trabalho será verificar se o uso da água na produção de cerveja é sustentável, tomando como parâmetro o preço implantado aos utilizadores e os custos pela utilização. O presente trabalho surge do contexto de que a água é fundamental para a manutenção e a sustentabilidade dos ecossistemas naturais e dos ciclos biogeoquímicos e da biodiversidade, os quais são cruciais para a própria sobrevivência do ser humano. No entanto, o aumento de demanda e a diversificação dos usos múltiplos intensificaram a crise hídrica, e a severidade e a complexidade dessas crises, as quais deverão ainda persistir por longos períodos. Essas crises demandam soluções que vão desde planejamento estratégico de longo prazo até medidas estruturais e de governança avançada (Cortes \& Torrente, 2015). Então, a redução da demanda doméstica e industrial é um imperativo e deve ser orientada por comunicação adequada, novos processos de gestão e mobilização e tecnologia avançada. Tecnologias para a redução da demanda doméstica devem ser incentivadas (Jimenez-Cisneros, 2015). 


\section{Metodologia}

Trata-se de uma pesquisa qualitativa, uma vez que a base de analise está na qualidade do discurso inseridas nos sistemas sociais com viés diretamente ligados aos sistemas ambientais dada aos produtores de cerveja a partir da tomada de decisão pelo pagamento ou não da água como um insumo a ser considerado no processo de produção, analisado caracteristicamente por indução (Pereira 2018); a indução por si só parte do particular deixando a generalização como um produto posterior, uma vez que a indução parte da premissa que os fatos e os fenômenos devem serem entendidos em principio e posterior compara-se as necessidades do conhecer o fenômeno como um todo (Gil, 2008). Nesse sentido, e entendendo a água como bem essencial e escasso, torná-la um insumo na produção de cerveja é essencial e, assim sendo a análise econômica dessa no processo produtivo é indispensável e assim sendo o método indutivo para a análise dos discursos que influencio os economistas clássicos em suas análises dos processos econômicos sociais e científicos (Gil, 2008).

Para análise econômica do uso da água na produção de cerveja foram adotados dois métodos de avaliação, a construção de uma função de produção ${ }^{1}$ e a avaliação da predisposição a pagar para se dispor de água na fábrica. Em tese a função de produção permite estabelecer um valor econômico para água, quando considerada um bem de produção como um insumo que propicia o aumento da produtividade, nesse caso, seu valor equivaleria a ganhos líquidos de produção, sendo determinado para diferentes produtores do mesmo grupo representado por um sistema de produção incorporado aos custos tradicionais 'trabalho, capital, equipamentos, insumos entre outros' interligados ao consumo de água a ser avaliado posteriormente (Cordeiro Neto, 1995).

Para avaliação da disposição a pagar pela água como um bem econômico, considerou-se um mercado fictício, estabelecido através de indícios de que os produtores estariam dispostos a pagar pela água utilizada na produção de cerveja afim de que esta estivesse disponível na fábrica, as informações para essa avaliação foram obtidas em artigos científicos sobre o assunto, nos anuários nacional da produção de cerveja de 2014 a 2020 e em notícias de jornais e revistas reconhecidas nacional e mundialmente a partir de entrevistas realizadas por esses veículos aos representantes de cinco marcas todas com mercado nacional e internacional, exceto a marca $\mathrm{X}$ que atual apenas em mercado nacional. O objetivo por essa busca foi perceber se os produtores manifestavam preferências por qual tipo de água utilizar e a partir dessa preferência avaliar a disposição marginal a pagar por diferentes cotas de volume de água no mercado fictício, podendo inclusive se estabelecer uma curva de demanda para cada marca consultada e posteriormente agrupar por semelhanças de preferência revelada e utilidade

${ }^{1}$ Se cada produtor indexado por $\mathrm{i}=1, \ldots, \mathrm{I}$, produzindo até $\mathrm{M}$ produtos, com a utilização de $\mathrm{N}$ insumos, a produção do $m$-ésimo produto, $\mathrm{Y}_{\mathrm{m}}$, requer a utilização do vetor insumo, $X_{\mathrm{m}}=\left(\mathrm{X}^{\mathrm{m}_{1}} \mathrm{X}^{\mathrm{m}} 2, \ldots, \mathrm{X}_{\mathrm{mn}}\right)$, simplificando, cada produto é produzido utilizando a função de produção $F_{\mathrm{m}}\left(\mathrm{X}_{\mathrm{m}}\right)$ admitindo que a tecnologia é passível de separação e a mesma para todos os produtores. Os insumos estão disponíveis em quantidade limitada por produto de acordo com o vetor $\mathrm{X}=\left(\mathrm{X}^{-1} 1_{\mathrm{X}^{-1}}{ }_{2}, \ldots \mathrm{X}^{-1} \mathrm{~m}\right)$ onde $\mathrm{X}^{-1} \mathrm{~m}$ denota a quantidade física disponível do $n$-ésimo insumo para $\mathrm{o}$ i-ésimo produto. Os produtores são tomadores de preços e determinam a quantidade a demandar de cada insumo, de acordo com a solução do problema de minimizar o custo total de produção.

$\mathrm{M}$

$\mathrm{C}_{1}\left(\mathrm{X}^{\mathrm{i}}, \mathrm{P}, \mathrm{Y}^{\mathrm{i}}\right)=\mathrm{Min} \quad \sum \mathrm{PX} \mathrm{M}$

$\left\{\mathrm{X}_{1}{ }_{1} \ldots \mathrm{X}_{\mathrm{m}}^{\mathrm{i}}\right\} \quad \mathrm{M}=1$

$F_{\mathrm{m}}\left(\mathrm{X}^{1} \mathrm{~m}\right) \geq \mathrm{Y}^{1}{ }_{\mathrm{m}}$ para $\mathrm{m}=1, \ldots, \mathrm{M}$

$\mathrm{X}^{1} \geq \sum \mathrm{X}_{\mathrm{m}}^{1}$

$\mathrm{M}=1$

Onde: $\mathrm{C}_{1}\left(\mathrm{X}^{-1}, \mathrm{P}, \mathrm{Y}\right)$ função custo de produção do produto $\mathrm{i}$;

$\mathrm{Y}^{1}=\left(\mathrm{Y}_{1}{ }_{1} \mathrm{Y}_{2}{ }_{2} \ldots \mathrm{Y}_{\mathrm{m}}^{\mathrm{i}}\right)^{\prime}$ é o vetor produção para o produto $\mathrm{i}$

$\mathrm{X}=\left(\mathrm{X}_{1}{ }_{1} \mathrm{X}_{2}{ }_{2} \ldots \mathrm{X}^{1} \mathrm{~m}\right)$ é o vetor insumo para o produtor i e $\mathrm{P} € \mathrm{R}_{+}^{\mathrm{N}_{+}}$é o vetor preço dos insumos. Sendo i o insumo água no mercado fictício. 
algumas das marcas ou excluir essa possibilidade em ambas.

A análise dos discursos deu-se por testes comparativos montando-se uma amostra aleatória retirada de recortes das falas dos entrevistados, selecionados aleatoriamente por grupos de interesse nas cinco marcas estudadas, nesse sentido, a pesquisa enquadra-se em qualitativa que para Pereira, et al., (2018, p. 67) "os métodos qualitativos são aqueles nos quais é importante a interpretação por parte do pesquisador”. É importante observar que nesse tipo de pesquisa a análise dos dados segue caminhos indutivos visto que os caminhos são focos em que "a preocupação do processo é predominante em relação à do produto" Pereira, et. al., (2018, p.67) nesse mesmo sentido define que o método indutivo segue via de regras características especificas para a pesquisa concreta da observação de casos específicos e observáveis, parte do particular e não deve ser buscadas particularidades (Gil,2008).

A seleção das entrevistas para compor a amostra foram escolhidas por representatividades de diferentes tipos de sistemas de produção e condições socioeconômicas dos produtores, assim como a existência em seus discursos de suas marcas serem ou não ambientalmente responsáveis pelas externalidades causadas no processo de produção, visando uma produção sustentável e, considerando especialmente em seu processo a decisão pelo uso da água considerando ganhos e perdas do valor desse recurso para os serviços ambientais promovido por ele. Por questões de tempo e recursos, consideraram-se como fatores principais a definir o tamanho da amostra o prazo e os custos, portanto foi escolhido uma amostra com erro amostral de 5\% e tamanho igual a 30 (trinta) entrevistas e artigos em conjunto, podendo desprezar eventuais entrevistas e/ou artigos que não atendessem ao propósito do estudo. A pesquisa ocorreu no período de agosto a outubro de 2020 e foi desenvolvida com apoio do banco de dados dos periódicos da CAPES/CAFE, Google acadêmico, Web of Science e nos anuários da produção nacional de cerveja entre 2014 e 2020.

\section{Resultados e Discussão}

Das cinco marcas consultadas, considerando o uso da água e a forma de captação obteve-se os seguintes resultados; as marcas que lideram o ranking nacional em comercialização apresentam uma preocupação quanto ao uso da água e sua relação com a sociedade, visto que a produção de cerveja demanda um alto consumo pelo recurso e assim sendo, demandam estudos e pesquisas na busca por um uso sustentável e responsável do recurso; as duas marcas menores com uma fatia menor de mercado entendem a preocupação, mas ainda não tem pesquisas diretamente relacionadas a tecnologias de melhor eficiência pelo uso da água, mas dão a entender que pagam direitos ao uso de tecnologias desenvolvidas pelas parcerias.

Ao se avaliar a predisposição a pagar pelo recurso em um mercado fictício de água, às três marcas líderes demonstram nos discursos de seus representantes já assim se comportarem, visto que utilizam um processo de reuso da água em etapas diferentes do processo produtivo e ao utilizarem algo em torno de $80 \%$ da água é de poços, o que ameniza as externalidades e apresentam-se ambientalmente responsáveis, com uma sustentabilidade aceitável dentro dos padrões dos órgãos fiscalizadores, já as duas marcas de menor fatia de mercado, demonstram entender a necessidade de aplicação de uma política dentro dos padrões dasmarcas líderes, mas ainda não a pratica dada a fatia de mercado não cobrir os custos, e que aparentam propensão a aplicabilidade da política de reuso, e melhoria nas tecnologias para eficiência no uso da água na produção de cerveja (Anuário da cerveja, 2020). Independente da fatia de mercado e da tecnologia desenvolvida para minimizar a quantidade de água utilizada na produção de cerveja, o melhor resultado obtido e observado é de 3,5 (três litros e meio) de água para produção de 1 (um) litro de cerveja, as duas cervejarias de menor participação e que afirmam não desenvolver tecnologias alcançam esses resultados a partir da utilização da tecnologia desenvolvidas pelas maiores e que para isso pagam os direitos (Anuário da cerveja, 2014). 
Todas as cinco marcas estudadas, afirmam estarem preocupadas com as questões ambientais, e, sobretudo com o uso do recurso água, visto que esse é o principal recurso na fabricação de cerveja, e que de acordo com a (CervBrasil, 2016), a partir de tecnologias desenvolvidas e aplicadas na produção de cerveja dos 4,5 (quatro litros e meio) de água utilizada reduziuse para 3,5 (três e meio) para produção de um litro de cerveja, resultado melhor que o projetado que era de 3,61 (três virgula sessenta e um) isto posto pela responsabilidade dessas companhias e de suas consorciadas com as questões ambientais e com o uso da água. Na temática responsabilidade pelo uso da água a (CervBrasil, 2016), afirma que entre suas ações para melhor eficiência desse recursos está o reaproveitamento de água (recirculação), captação de água de chuvas, preservação de bacias hidrográficas, por meio de projetos próprios e em participação no Comitê de Bacias Hidrográficas comandado pela (ANA) Agência Nacional de Águas; essas ações vinculadas ao preço pago pelo recurso e inserção desse recurso no mercado como insumo promovendo uma melhoria na produção e uma capacidade competitiva em condições normais que para o Brasil, essa política tem resultado em melhorias quantitativas na produção e qualitativa na redução de externalidades negativas, melhorando inclusive a posição brasileira no ranking mundial da produção de cerveja. o Brasil ocupa o terceiro lugar no ranking mundial da produção de cerveja, ficando atrás apenas da China e dos Estados Unidos são responsável por 1,6\% do PIB - Produto Interno Bruto nacional,recolhendo mais de R 20 (Vinte) bilhões de reais em tributos em todo o país (Anuário da cerveja,2015).

Tabela 1 - Produção Mundial de cerveja cinco maiores produtores mundiais e os cinco maiores consumidores mundiais

\begin{tabular}{|c|c|c|}
\hline País & Produção em milhões de L & Consumopor habitante em L \\
\hline China & 381,2 & - \\
\hline Estados unidos & 214,6 & - \\
\hline Brasil & 114,4 & - \\
\hline México & 119,8 & - \\
\hline Alemanha & 93,7 & - \\
\hline República Tcheca & - & 143 \\
\hline Austria & - & 108 \\
\hline Alemanha & - & 107 \\
\hline Irlanda & - & 94 \\
\hline Polônia & - & 89 \\
\hline
\end{tabular}

Fonte: Catalise, 2018 Anuário, 2014 a 2020, adaptado para o trabalho.

De acordo com a tabela 1, os maiores produtores não são os maiores consumidores, dos produtores apenas a Alemanha aparece em terceiro lugar como maior consumidor e em quinto na produção, o que pode ser entendido que se o principal recurso na produção é água e esse é um produto tipicamente comercializado no mercado externo, então tem-se uma 
vazão desses recursos na ordem de $89 \%$, considerando $11 \%$ em consumo interno, exceto para Alemanha que aparece nos dois lados da equação como alto produtor e alto consumidor.

Visto a equação do ponto de vista da vazão dos mercados internos para os mercados externos, considerando a produção e o alto consumo de água pelo mercado produtor, tem-se uma vazão do recurso desses mercados para um injeção nos mercados consumidores, assim sendo é mister na função de produção o valor do recurso água estimado como insumo, aumentando a produção e assim sendo devolvido em forma de recursos financeiros aos países produtores, compreendido essa relação a partir da descrição a seguir. Na função de produção o valor do recurso água é estimado como insumo ou fator de produção de um outro produto, de modo que apenas estima uma curva de demanda, por isso aconselha-se adotar para esse caso a terminologia 'curva de ganho', buscando dados que demonstre o consumo d'água no processo produtivo, percebendo a renda anual bruta e liquida.

Os valores dos custos de produção para cada fabrica/país avaliados a partir do sistema de custos de produção contratado pela própria indústria e/ou consorcio de país ou no país produtor; as rendas brutas calculadas a partir da produção e valorando com base na média anual de preços de comercialização do produto no atacado, considerando os países consumidores assim como os mercados internos; as rendas liquidas calculadas subtraindo das rendas brutas, os custos de produção calculados de acordo de acordo com a renda teórica obtida com a comercialização e assim sendo a renda teórica obtém-se com a hipótese de que o produto exerce a atividade considerando o preço da água nos padrões comuns utilizados a partir dos serviços públicos de abastecimento.

O valor da água considera-se ceterisparibus com o aumento médio da produtividade decorrente do uso dos recursos como insumo, estimando o valor da água como um bem de produção, e sendo considerado um insumo que serve para aumentar a produção, seu valor pode ser considerado equivalente ao ganho líquido da produção alcançada (Cordeiro neto, 1995), e, considerando a decisão de utilizar a água como insumo parte da premissa que os custos adicionais seriam compensados com os rendimentos a mais graças ao aumento da produtividade (Fernandez, 1996).

Pela descrição acima é mister calcular o valor dos ganhos líquidos do produto, no caso, cerveja como: a renda bruta anual por tipo de produto produzido, o valor da renda do produto considerando a água como insumo em comparação ao produto com ausência dessa consideração, adicionar o valor da depreciação do produto o custo de oportunidade do capital empregado no sistema de captação de água entendendo-a como insumo.

Nesse processo, calcula-se a renda líquida, os custos de produção e comercialização, diminuindo da renda líquida calculando o valor do produto considerando o custo de depreciação e oportunidade, podendo-se obter o ganho do produto a ser atribuído à água como insumo e do produto que não a considera, assim, dividindo-se o valor do ganho liquido pelo consumo médio anual da água como insumo, obtém-se o valor médio unitário que poderia ser atribuído ao metro cúbico de água utilizada na produção de cerveja como insumo. Ver Tabelas 2 e 3 a seguir. 
Tabela 2 - ganho líquido médio de produto utilizando a água como insumo

\begin{tabular}{c|c|c|c}
\hline \multirow{2}{*}{} & \multicolumn{3}{|c}{ Renda líquida média anual calculada (1 R\$/l) } \\
\cline { 2 - 4 } & $\begin{array}{c}\text { Renda do Produtor } \\
\text { considerando água como } \\
\text { insumo }\end{array}$ & $\begin{array}{c}\text { Renda da produção } \\
\text { considerando água não } \\
\text { como insumo } \\
\text { depreciação + } \\
\text { oportunidade }\end{array}$ & Ganhos líquidos \\
& $(1)$ & $(1)-(2)$ & \\
\hline A & 6,476 & 2,651 & 3,825 \\
\hline B & 6,685 & 2,967 & 0,107 \\
\hline FA-B & - & - & 3,718 \\
\hline
\end{tabular}

Fonte: Anuário 2020 adaptado para o trabalho.

De acordo com a tabela 2, ocorre ganhos líquidos nos dois casos tanto para A quanto para B, e, uma leve oscilação positiva de 0,107 em ganhos líquidos para A em comparação a B, esse ganho sendo explicado de acordo com as tecnologias utilizadas considerando que A possui tecnologia própria para redução do uso da água na produção e B utiliza-se das tecnologias desenvolvidas por A, de acordo com a descrição acima, sendo A empresas que lideram o mercado e B empresas em via de dominação que vivem atualmente de consórcios com as líderes.

Tabela 3 - Valor Médio unitário do metro cúbico de água em R \$ com base no ganho líquido calculado.

\begin{tabular}{c|c|c|c}
\hline Produtor & Ganho Líquido & $\begin{array}{l}\text { Consumo Médio anual } \\
\text { de água }\left(\mathrm{m}^{3} / \mathrm{l} / \mathrm{ano}\right)\end{array}$ & $\begin{array}{l}\text { Valor Ganho unitário } \\
\text { por ano }\left(\mathrm{R} \$ / \mathrm{m}^{3}\right)\end{array}$ \\
\hline A & 3,825 & 16.254 & 11.245 \\
\hline B & 3.718 & 14.141 & 43 \\
\hline fA-B & - & - & 11.202 \\
\hline
\end{tabular}

Fonte: Anuário, 2020 adaptado para o trabalho.

De acordo com a tabela 3, há uma leve oscilação para cima de $\mathrm{R} \$ 43,00$ (quarenta e três reais) de $\mathrm{A}$ em relação a $\mathrm{B}$, isto explicado pelos mesmos motivos do uso de tecnologia própria de A em relação a B que faz parte de grupos produtores de menor poder aquisitivo, que se utiliza das tecnologias dos grupos de maior poder.

O valor encontrado agrega o valor máximo médio ao aumento da renda usando a água como instrumento de aumento da produtividade com base em critérios de renda calculada comparando os valores obtidos a partir da renda liquida declarada pela função de produção, na tabela 2 , demonstra-se o quadro de resultados para os valores médios referentes a $1.000 \mathrm{~m}^{3}$ de 
consumo de água, de modo que percebe-se que os resultados encontrados quando comparados os valores de disponibilidade a pagar pela água como insumo e o valor decorrente da renda liquida declarada para a utilização desse recurso são aproximados e apresentam-se e relação a avaliação como uma consistência para o uso da água como insumo, ver Tabela 4.

Tabela 4 - valor médio unitário do $\mathrm{m}^{3}$ de água em $\mathrm{R} \$$ em relação à renda liquida declarada

\begin{tabular}{c|c|c|c|c}
\hline Produtor & $\begin{array}{l}\text { Consumo direto } \\
\mathrm{m} 3\end{array}$ & $\begin{array}{l}\text { Consumo anual } \\
\left(1.000 \mathrm{~m}^{3}\right)\end{array}$ & $\begin{array}{l}\text { Renda liquida } \\
\text { declarada }\end{array}$ & $\begin{array}{l}\text { Custo unitário } \\
\left(\mathrm{R} \$ / \mathrm{m}^{3}\right)\end{array}$ \\
\hline A & 44.530 & 16.245 & 1.010 & 0,06211 \\
\hline B & 38.744 & 14.143 & 1.207 & 0,08458 \\
\hline
\end{tabular}

Fonte: Anuário, 2020, adaptado para o trabalho.

Ao observar a tabela 4, percebe-se que aos que detém tecnologia para uso eficiente da água no caso os produtores do grupo A apresentam melhores resultados em relação aos que não detém e aplicam a política de eficiência do uso da água a partir de consórcio no caso os produtores do grupo B, ainda assim percebe-se que utilizar a água como insumo é uma alternativa eficiente visto do ponto de vista da vazão do recurso e considerando que o mercado devolve em forma de recursos financeiros a vazão ora mensurada, considerando o pagamento desse recursos em metros cúbicos, ver tabela 5.

Tabela 5 - Valores em reais para $1.000 \mathrm{~m}^{3}$ de água

\begin{tabular}{l|l|l|l}
\hline Produtor & Água como insumo & Função de produção \\
\hline & & Declarada & Calculada \\
\hline A & 35,49 & 62,11 & 235,34 \\
\hline B & & & 262,71 \\
\hline
\end{tabular}

Fonte: Anuário da Cerveja, 2020, adaptado para o trabalho.

É notória a ausência de tecnologia no aumento dos cursos, de modo que quem detém as técnicas poupa um pouco mais ao fechar a conta, isto fica claro quando observado o valor calculado na função de produção, há um ganho de $\mathrm{R} \$ 24,37$ (Vinte e quatro reais e trinta e sete centavos) de A em relação a B, considerando a tecnologia utilizada, a responsabilidade social e o equilíbrio do uso do recurso água como insumo na produção de cerveja. Uma vez que os valores obtidos por intermédio da renda calculada ser significativamente maiores, refletem os valores decorrentes da renda obtidos quando os valores de mercado são utilizados para comercializar o produto, os valores calculados ainda bem mais altos quando comparados com os valores declarados refletem a contribuição da água dentro do processo produtivo e, evidencia que o Grupo A está em vantagem ao Grupo B visto os investimentos iniciais em tecnologia. 


\section{Conclusão}

O artigo demonstrou que há uma percepção da importância da água para o setor cervejeiro e que esse tem implementado ações tanto para preservação das bacias hidrográficas, como também para diminuir o impacto da produção. Para isso há um investimento em tecnologias pelas principais fábricas de cerveja para preservação dos recursos naturais especialmente a água. Constatou-se, que os principais países produtores não são os maiores consumidores assim sendo há uma vazão do recurso água dos países produtores para os consumidores. Ao analisar os gráficos e os resultados se percebe que havendo uma vazão e a água sendo considerando como insumo na função de produção o valor agregado pode ser repassado ao consumidor e assim sendo a vazão passa a ser compensada pelos recursos financeiros devolvidos aos países produtores. Por fim, nota-se que a propensão a pagar pelo recurso é tratada a partir dos discursos dos representantes como já sendo feito a partir dos investimentos em tecnologias para maior impactar no meio ambiente e diminuição das externalidades negativas.

Nesse sentido, o pensamento positivo na diminuição das externalidades negativas, partindo do ponto de vista de que já há investimentos em tecnologias que minimizam os danos aos recursos naturais em especial a água e que evidencia-se a vazão desse recursos as diferentes nacionalidades, ainda que essa vazão seja compensada por devolutivas monetárias, aconselha-se a trabalhos futuros buscar por meios de dados estatísticos o quão significativa é essa vazão e os retornos financeiros se são equiparados aos serviços ambientais que a água deixa de executar ao ser usada na produção de cerveja. Para essa análise comparativa, aconselha-se o uso das contas ambientais nacionais como base para comparação com as demais economias envolvidas no processo, de igual modo torna-se interessante averiguar em conjunto os demais recursos utilizados na produção de cerveja e que ao longo de seu processo utilizou água, nesse caso a utilização da pegada ecológica como indicador e do modelo pressão estado resposta, seguido do modelo pressão estado impacto resposta para averiguação dos dados da vazão do recurso a partir dos resultados nesse trabalho alcançados que demonstram a vazão do recurso.

Os aconselhamentos acima são pertinentes partindo do pressuposto que nesse trabalho foi considerado apenas a água como inumo e essa sendo utilizada in natura, desconsiderando os demais recursos que ao longo de sua constituição utilizou-se em algum momento ou em todo o momento e que ao ser utilizado na produção de cerveja foi desconsiderado do cálculo do custo do recurso água nesse trabalho. Dentre todos os outros recursos a água utilizada para o cultivo do malte, da levedura e do lúpulo podem ser utilizados e acrescentados ao cálculo, como também outros tipos que para efeito de análise nesse estudo não foi considerada.

\section{Agradecimentos}

O presente trabalho foi realizado com apoio do Conselho Nacional de Desenvolvimento Científico e Tecnológico (CNPq).

\section{Referências}

Cordeiro Netto, O. M. A estimativa de um valor econômico para o uso da água como um dos elementos integrantes de gestão racional dos recursos hídricos. Seminários sobre a água, 2016. Brasília anais.

Cordeiro Netto, O. M. A estimativa do valor econômico da água: uma discussão teórica. In simpósio brasileiro de Recursos Hídricos, 11.: simpósio de hidráulica dos países de língua oficial Portuguesa. 2. 1995, Recife, Anais, Recife; ABRH, 1995. P.45-449.

Cordeiro, J. A. D. (2003). Abundância e escassez da água: a cobrança pelo uso-um modelo de formação de preços aplicável à bacia hidrográfica GL-1, Pernambuco (Master's thesis, Universidade Federal de Pernambuco).

Côrtes, P. L., Torrente, M., Pinto Alves Pinto, A., Ruiz, M. S., Dias, A. J. G., \& Rodrigues, R. (2015). Crise de abastecimento de água em São Paulo e falta de planejamento estratégico. Estudos Avançados, 29(84), 7-26.

Fernandez, J. C. (1996). Projeto de implantação da cobrança pelo uso e poluição da água dos mananciais do Alto Paraguaçu e Itapicuru. Salvador: Superintendência de Recursos Hídricos do Governo do Estado da Bahia. 
Research, Society and Development, v. 10, n. 2, e51710212765, 2021

(CC BY 4.0) | ISSN 2525-3409 | DOI: http://dx.doi.org/10.33448/rsd-v10i2.12765

Fillaudeau, L., Blanpain-Avet, P., \& Daufin, G. (2006). Water, wastewater and waste management in brewing industries. Journal of cleaner production, 14(5), 463-471.

Fragoso, R. M. D. S. (2001). Avaliação dos impactos sócio-económicos do plano de rega de Alqueva no sector agrícola do Alentejo: o caso do bloco de rega da infra-estrutura 12 .

Gil, A. C. (2008). Métodos e técnicas de pesquisa social. 6. ed. Ediitora Atlas SA.

Gleick, P. H. (2000). A look at twenty-first century water resources development. Water international, 25(1), 127-138.

Hal, R. V. (1992). Microeconomic analysis. WW Norton \& Company, Inc.

Henriques, P. D. D. S., Branco, M. C., Fragoso, R. M. D. S., \& Carvalho, M. L. D. S. (2006). Direito de acesso à água-princípios económicos para seu usufruto na agricultura.

Jimenez-Cisneros, B. (2015). Responding to the challenges of water security: the Eighth Phase of the International Hydrological Programme, 2014-2021. Proceedings of the International Association of Hydrological Sciences, 366, 10-19.

Junior, A. A. M., \& de Barros, Z. X. (2020). Utilização Racional De Água Em Cervejaria Brasileira. Energia Na Agricultura, 35(2), $287-294$.

Junior, A. A., Vieira, A. G., \& Ferreira, T. P. (2009). Processo de produção de cerveja. Revista Processos Químicos, 3(6), 61-71.

Mathias, T. R. S., MELlO, P. D., \& Servulo, E. F. C. (2014). Caracterização de resíduos cervejeiros. In Congresso Brasileiro de Engenharia Química (Vol. 20, pp. 1-8).

Mega, J. F., Neves, E., \& ANDRADE, C. J. D. (2011). A produção de cerveja no Brasil. Revista Citino, 1(1), 34-42.

Pereira, A. S., Shitsuka, D. M., Parreira, F. J., \& Shitsuka, R. (2018). Metodologia da pesquisa científica.

Trommer, M. (2011). Brasilien-Bier markt mit Potenzial. Brauwelt. Hans Carl Fachverlag. Germany.

Tsur, Y., Roe, T. L., Doukkali, M. R., \& Dinar, A. (2004). Pricing irrigation water: Principles and cases from developing countries. Resources for the Future. 